\title{
THE WORDING OF A CONTRACT IN ELECTRONIC FORM ${ }^{1}$
}

\author{
Marina Yu. Kozlova \\ Volgograd State University, Volgograd, Russian Federation
}

\begin{abstract}
Introduction: in the modern economy, registering the wording of a contract with the help of electronic documents has acquired the character of a stable trend. The aim of the study is to identify the main trends in the practice of exchanging electronic documents for the conclusion or execution of a civil contract. The paper uses the methods of description and interpretation; the theoretical methods of formal and dialectical logic. Results: the main reasons why the agreement of the parties is put in the form of a written document are determined. The judicial practice positions concerning the recognition of a message exchange by e-mail, text messages in the messengers, as a form of the civil contract are studied. It is established that the agreement of the parties shall determine the possibility of exchanging electronic documents, and the addressee and sender of electronic messages shall be identified: if the message reliably comes from the party under the contract and is received by the other party, the content of this message binds the parties. In the study of the problem of binding the affiliate entity by the agreement concluded by purchasing or ordering services on the Internet, it is determined that in the vast majority of cases, consumers are not familiar with the terms of contracts that they conclude. And although the ignorance of the actual information about the contract does not entail, as a rule, the negative consequences for the buyer (customer), in the event of a conflict, the court may conclude that the consumer is not bound by the terms of the contract to which he acceded, due to the fact that he did not understand its meaning. Conclusions: an electronic document - a scanned copy of a paper document, a letter sent by e-mail, a document posted on the company's website as an accession agreement - is a full-fledged document in which the will of the parties to the agreement can be expressed. The specifics of electronic forms require establishing the possibility to identify the person issuing the document confirming the fact of a conscious accession to the agreement, determining the precise content of the agreement.
\end{abstract}

Key words: contract, contract form, electronic document, exchange of electronic documents, the Internet trade.

Citation. Kozlova M.Yu. The Wording of a Contract in Electronic Form. Legal Concept, 2019, vol. 18, no. 4, pp. 48-53. (in Russian). DOI: https://doi.org/10.15688/lc.jvolsu.2019.4.6

\section{ТЕКСТ ДОГОВОРА В ЭЛЕКТРОННОЙ ФОРМЕ ${ }^{1}$}

\author{
Марина Юрьевна Козлова \\ Волгоградский государственный университет, г. Волгоград, Российская Федерация
}

Введение: в современной экономике оформление текста договора с помощью электронных документов приобрело характер устойчивой тенденции. Цель исследования: выявить основные направления развития в практике обмена электронными документами для заключения или исполнения гражданско-правового договора. В статье используются методы описания и интерпретации; теоретические методы формальной и диалектической логики. Результаты: определены основные причины, в силу которых соглашение сторон облекается в форму письменного документа. Изучены позиции судебной практики относительно признания обмена сообщениями по электронной почте, текстовыми сообщениями в мессенджерах формой гражданско-правового договора. Установлено, что соглашением сторон должна быть определена возможность обмена электронными документами, а адресат и отправитель электронных сообщений - идентифицироваться: если сообщение достоверно исходит от стороны по договору и получено другой стороной, то его содержа- 
ние связывает их. При исследовании проблемы связанности присоединившегося субъъекта соглашением, заключенным путем покупок или заказа услуг в Интернете, выявлено, что в подавляющем большинстве случаев потребители не знакомятся с условиями договоров. Незнание действительной информации о договоре не влечет, как правило, негативных последствий для покупателя (заказчика), поэтому при возникновении конфликта суд может прийти к выводу о несвязанности потребителя условиями договора, к которому он присоединился в силу того, что не уяснил его смысл. Выводы: электронный документ - сканированная копия бумажного документа, письмо, направленное по электронной почте, документ, размещенный на сайте компании в качестве договора присоединения. Он является полноценным документом, выражающим волю сторон договора. Специфика электронной формы требует установления возможности идентифицировать лицо, от которого исходит документ, подтверждения факта осознанного присоединения к договору, определения точного содержания соглашения.

Ключевые слова: договор, форма договора, электронный документ, обмен электронными документами, интернет-торговля.

Цитирование. Козлова М. Ю. Текст договора в электронной форме // Legal Concept $=$ Правовая парадигма. -2019. - Т. 18, № 4. - С. 48-53. - DOI: https://doi.org/10.15688/lc.jvolsu.2019.4.6

\section{Введение}

Для большинства договоров, заключаемых в соответствии с российским гражданским законодательством, требуется письменная форма: договор должен существовать в виде единого документа, подписанного сторонами, или нескольких документов, которыми обмениваются стороны. В этом случае правовые последствия заключенной сделки возникают с момента облечения ее в письменную форму. Такая форма обеспечивает интересы как самих контрагентов, воля которых приобретает определенность и окончательность, так и третьих лиц, получающих возможность уяснить содержание соглашения сторон.

Цифровизация экономики, подразумевающая компьютерную алгоритмизацию производственных, транспортных, коммуникационных и других процессов [1, с. 31], порождает, соответственно, и электронный документооборот. Электронный документ имеет безусловные отличия от бумажного, поскольку в него технически проще внести изменения, но сложнее обнаружить и доказать их. Его авторство может быть подтверждено только на основании презумпции авторства того лица, от которого исходит документ. В то же время документ в электронной форме скорее рассматривается участниками оборота в качестве копии, требующей подтверждения на бумаге. Перед правом стоят проблемы определения минимально необходимых признаков, которые достаточны для признания электронного документа или обмена электронными документами, договором, а также связанности лица, присоединяющегося к договору путем совершения действий в сети Интернет.

\section{Текст договора,}

\section{заключенного путем обмена сообщениями}

\section{в электронной форме}

В связи с развитием технологий стороны предпочитают обмениваться электронными документами, в частности по электронной почте, хотя не всегда такого рода обмен признается заключением договора. Суду должны быть представлены доказательства того, что лицо, осуществляющее переписку, имело полномочия действовать от имени контрагента и направляло сообщения в адрес другой стороны договора. Действует презумпция, в соответствии с которой письмо, отправленное с электронного почтового ящика, указанного в официальных документах, считается сообщением стороны договора. Хотя следует учитывать, что идентификация лица, направившего его, в какой-то мере носит условный характер - действия, совершаемые в Интернете, не имеют столь явно выраженной привязки к конкретной личности и могут быть совершены кем угодно [8]. Договор может заключаться посредством и сообщений по электронной почте, и обмена сканированными копиями документов.

О договорных отношениях может свидетельствовать переписка по электронной почте в совокупности с совершением каких-либо активных действий в пользу одного из участ- 
ников отношений (например, оплаты) [2]. Само по себе наличие переписки не всегда свидетельствует о заключении договора, поскольку стороны могут не прийти к соглашению по поводу его существенных условий.

Получение или отправка сообщения с использованием адреса электронной почты, известного как почта самого лица или служебная почта его компетентного сотрудника, свидетельствует о совершении этих действий самим лицом, пока им не доказано обратное (при установлении соблюдения порядка проведения проверки и изъятия доказательств) [5].

Полномочия лица, осуществляющего переписку от имени контрагента, должны быть подтверждены, иначе обмен документами по поводу заключения договора не может подтверждать факт его заключения [4]. Если стороны в своем соглашении условились о признании юридической силы документов, направляемых по электронной почте, то игнорирование сообщений почты рассматривается как уклонение от исполнения обязательств [6].

В качестве доказательства заключения договора путем обмена электронными письмами суды рассматривают их распечатку с указанием адресов электронной почты и времени отправления. При этом должно быть предоставлено подтверждение принадлежности электронной почты тому или иному контрагенту: это может быть как условие договора, так и указание на официальных бланке или сайте организации. Стороны спора могут обратиться к нотариусу за удостоверением доказательства - электронной переписки, а также дать суду возможность непосредственно обозреть переписку. Как правило, стороны не только определяют официальные адреса электронной почты, но и указывают конкретного работника, ответственного за взаимодействие с контрагентом, и сообщения посредством электронного адреса такого работника также принимаются во внимание.

Контрагенты могут своим соглашением исключить возможность общения посредством электронной почты, определив перечень способов передачи сообщений. Однако чаще всего стороны, напротив, согласовывают возможность переписки по электронной почте. Типичным условием является, например, следующее: «Стороны договорились вести ин- формационный обмен с использованием адресов электронной почты, указанных в реквизитах сторон договора».

Судами в качестве доказательств по спорам, связанным с договорными отношениями, принимаются во внимание сообщения не только по электронной почте, но и в мессенджерах (например, WhatsApp). Обычно сообщениями в мессенджерах и социальных сетях стороны обмениваются уже в процессе исполнения договора, например, при обнаружении каких-либо недостатков товара или услуги. В частности, в них может содержаться информация о принятии всей партии товара без каких-либо оговорок [7]. В случае если стороны договора пришли к соглашению о необходимости составления какого-либо письменного документа при обнаружении недостатков товара или услуг, обмен сообщениями в мессенджерах не будет рассматриваться как доказательство существования указанных недостатков. Кроме того, если стороны в договоре определили порядок обмена юридически значимыми сообщениями, то суды не принимают подобную переписку в качестве надлежащего доказательства [3].

Переписка может быть рассмотрена как подтверждение существования договорных отношений, если отправитель и получатель однозначно идентифицируются. Необходимо учитывать, что в мессенджерах обычно используется разговорный язык, а не деловой, что не всегда позволяет доподлинно установить смысл текста, а также принадлежность переписки к согласованию условий договора или его исполнению.

В случае если договор заключается посредством обмена сообщений по электронной почте, отсутствует единый текст, из которого следуют условия соглашения. Содержание соглашения возможно установить исключительно на основе текста писем, документов, а также фактических действий сторон. Обмен сканированными копиями бумажных документов позволяет более точно согласовать волю сторон. В процессе обмена документами по электронной почте принципиальным является вопрос об идентификации сторон соглашения: если сообщение достоверно исходит от стороны по договору и получено другой стороной, то содержание этого сообщения связывает их. 


\section{Текст договора, заключенного путем присоединения к предложению контрагента в сети Интернет}

Предложение заключить договор может содержаться в самостоятельном документе, размещаемом в сети Интернет и прямо именуемом публичной офертой. Договор также может быть заключен путем совершения действий через веб-сайт (например, покупка товаров, заказ услуг через интернет-магазин, или интернет-аукцион, а также посредством приложений для смартфона). Как раз на подобные ситуации рассчитана новая редакция ст. 160 ГК РФ, действующая с 1 октября 2019 г., устанавливающая правило, согласно которому письменная форма сделки считается соблюденной, если сделка совершена с помощью электронных и других технических средств.

Например, договоры могут заключаться путем подтверждения согласия в предлагаемых формах на сайте или использования функционала сайта / мобильного приложения. Как правило, такие договоры заключаются с потребителями, то есть физическими лицами, которые заказывают товары или услуги для своих личных нужд. При заключении подобных договоров используется прием, предполагающий отсылку к иным документам, имеющимся на сайте, что отличает такого рода потребительские договоры и ставит потребителя в невыгодное, по сравнению с предпринимателем, положение. Таким образом, требуются значительные затраты времени и усилий для того, чтобы выяснить действительные условия договора.

Кроме того, текст договора является типовым, составляется продавцом или исполнителем и потенциально может содержать несправедливые для присоединяющейся стороны условия. Как указывается в п. 1 ст. 3 Директивы Совета Европейских сообществ от 5 апреля 1993 г. «О несправедливых условиях в договорах с потребителями» (93/13/ЕЭС), договорное условие несправедливо, если приводит к значительному дисбалансу в правах и обязанностях в ущерб потребителю [10].

Основной юридической проблемой является связанность потребителя условиями соглашения в том случае, если он в действитель- ности не ознакомился с ними. Согласно исследованиям даже для соглашений, где потребители должны подтвердить, что они прочитали и согласились с условиями, прежде чем покупать продукт, и эти условия заметны и доступны, процент людей, которые действительно прочитали их, находится в диапазоне от 0,05 до $0,22 \%$ [9]. Несмотря на то, что продавец или исполнитель должны обеспечить возможность ознакомиться с условиями договора, реально контролировать этот процесс практически невозможно. Поэтому не исключено, что при возникновении конфликта суд может прийти к выводу о несвязанности потребителя условиями договора, к которому он присоединился.

Размещение формуляра договора таким образом, чтобы потребитель обязательно ознакомился с ним, должно способствовать информированию потребителя и защите его интересов. При этом нельзя не принимать во внимание то обстоятельство, что потребитель некритически относится к условиям договора, осуществляемого посредством сети Интернет, и подписывается под условиями, даже если они несправедливые. В то же время следует признать, что онлайн-торговля носит массовый характер, сумма сделки не является значительной для покупателя (заказчика), поэтому незнание действительной информации о заключаемом договоре, как правило, не влечет для него негативных последствий. Кроме того, эффективными можно признать процедуры разрешения споров, используемых на крупных торговых площадках, таких как AliExpress: это так называемые «споры», которые ведутся сначала с продавцом, а затем с администрацией торговой площадки, и завершаются в большинстве случаев удовлетворением требований потребителя.

\section{Выводы}

Текст гражданско-правового договора может содержаться в электронных документах, которыми обмениваются стороны или к которым присоединяется одна сторона по предложению другой в сети Интернет. К электронным документам относятся: сканированная копия бумажного документа, письмо, направленное по электронной почте, документ, раз- 
мещенный на сайте компании в качестве договора присоединения. Специфика электронной формы требует установления возможности идентифицировать лицо, от которого исходит документ, подтверждения факта осознанного присоединения к договору, определения точного содержания соглашения. При этих условиях текст соглашения сторон будет содержаться в электронных документах, а обмен - считаться соблюдением письменной формы.

\section{ПРИМЕЧАНИЕ}

${ }^{1}$ Исследование выполнено при финансовой поддержке РФФИ в рамках научного проекта № 19-011-00251 «Тенденции развития языковых средств юридической техники гражданско-правового договора».

The reported study was funded by RFBR according to the research project № 19-011-00251 "The tendencies of juridical technique's language means development in civil contract".

\section{СПИСОК ЛИТЕРАТУРЫ}

1. Гончаров, А. И. Цифровые токены в инструментарии современной внешнеторговой деятельности хозяйствующих субъектов юрисдикций БРИКС /А. И. Гончаров, М. В. Гончарова // Legal Concept $=$ Правовая парадигма. $-2019 .-$ T. 18, № 3. C. 31-42. -(На англ.). - DOI: https://doi.org/10.15688/ lc.jvolsu.2019.3.5.

2. Определение Верховного Суда Российской Федерации от 19.03.2019 № 19-КГ18-49. - Электрон. текстовые дан. - Режим доступа: http://vsrf.ru/ stor pdf.php?id=1754708 (дата обращения: 30.08.2019). - Загл. с экрана.

3. Постановление Арбитражного суда Северо-Западного округа от 22.08.2019 по делу № А5654185/2018. - Электрон. текстовые дан. - Режим доступа: https://kad.arbitr.ru/Card/7d51458f-a394-40fba88c-817e504ee2ce (дата обращения: 05.09.2019). Загл. с экрана.

4. Постановление Двадцатого арбитражного апелляционного суда от 01.04.2019 по делу № А623369/2018. - Электрон. текстовые дан. - Режим доступа: https://kad.arbitr.ru/Card/8049f9d2-a5fa-43d2be4d-c67cf014fc24 (дата обращения: 20.07.2019). Загл. с экрана.

5. Постановление Президиума Высшего Арбитражного Суда Российской Федерации от 12.11.2013 № 18002/12. - Электрон. текстовые дан. Режим доступа: http://www.arbitr.ru/bras.net/ f.aspx?id_casedoc $=1$ 1_50541280-07f7-48b2-b0c08d561b047348 (дата обращения: 20.07.2019). - Загл. с экрана.

6. Решение Арбитражного суда г. Москвы от 29.03.2019 по делу № A40-26540/18-3-185. - Электрон. текстовые дан. - Режим доступа: https://kad.arbitr.ru/ Card/8fdd4555-6e96-4526-99d4-5c9cf0fe4d6e (дата обращения: 25.08.2019). - Загл. с экрана.

7. Решение Арбитражного суда Новосибирской области по делу от 29.03.2019 № А45-17427/ 2018. - Электрон. текстовые дан. - Режим доступа: https://kad.arbitr.ru/Card/433a97a1-6f0f-4049-b7589f591b6b4480 (дата обращения: 22.08.2019). - Загл. с экрана.

8. Савельев, А. И. Электронная коммерция в России и за рубежом: правовое регулирование /А. И. Савельев. -2-е изд. - М. : Статут, 2016. -640 с.

9. Bakos, Ya. Does Anyone Read the Fine Print? Consumer Attention to Standard Form Contracts (January 1, 2014) / Ya. Bakos, F. Marotta-Wurgler, D.R. Trossen // Journal of Legal Studies. - 2014. - Jan., vol. 43, № 1. -P. 1-35. - DOI: http://dx.doi.org/10.2139/ ssrn. 1443256.

10. Council Directive 93/13/EEC of 5 April 1993 on unfair terms in consumer contracts. - Electronic text data. - Mode of access: https://eur-lex.europa.eu/ LexUriServ/LexUriServ.do? uri=CELEX: 31993L0013:en:HTML (date of access: 28.08.2019).

\section{REFERENCES}

1. Goncharov A.I., Goncharova M.V. Tsifrovye tokeny $\mathrm{v}$ instrumentarii sovremennoy vneshnetorgovoy deyatelnosty khozyaystvuyushchikh subyektov yurisdiktsii BRIKS [Digital Tokens in the Tools of Modern Foreign Trade Activities by Economic Entities of the BRICS Jurisdictions]. Legal Concept = Pravovaya paradigma, 2019, vol. 18, no. 3, pp. 31-42. DOI: https:// doi.org/10.15688/lc.jvolsu.2019.3.5.

2. Opredelenie Verkhovnogo Suda Rossiyskoy Federatsii ot 19.03.2019 № 19-KG18-49 [Determination of the Supreme Court in Case 19 KG1849 Dated March 19, 2019]. URL: http://vsrf.ru/ stor_pdf.php?id=1754708 (accessed 30 August 2019).

3. Postanovlenie Arbitrazhnogo suda SeveroZapadnogo okruga ot 22.08.2019 po delu № A56$54185 / 2018$ [Resolution of the Arbitration Court of the North-Western District in Case No A56-54185/2018 Dated August, 22, 2019]. URL: https://kad.arbitr.ru/ Card/7d51458f-a394-40fb-a88c-817e504ee2ce (accessed 5 September 2019).

4. Postanovlenie Dvadtsatogo arbitrazhnogo apellyatsionnogo suda ot 01.04.2019 po delu № A623369/2018 [Resolution of the Twentieth Arbitration Court of Appeal in case No A62-3369/2018 dated 
April 1, 2019]. URL: https://kad.arbitr.ru/Card/ 8049f9d2-a5fa-43d2-be4d-c67cf014fc24 (accessed 20 July2019).

5. Postanovlenie Prezidiuma Vysshego Arbitrazhnogo Suda Rossiyskoy Federatsii ot 12.11.2013 №18002/12 [Resolution of the Presidium of the Supreme Arbitration court of the Russian Federation of 12.11.2013 № 18002/12]. URL: http://www.arbitr.ru/ bras.net/f.aspx?id casedoc $=11$ 50541280-07f7-48b2b0c0-8d561b047348 (accessed 20 July 2019).

6. Reshenie Arbitrazhnogo suda g. Moskvy ot 29.03.2019 po delu № A40-26540/18-3-185 [The Decision of the Arbitration Court of Moscow in Case No A40-26540/18-3-185 Dated March 29, 2019]. URL: https://kad.arbitr.ru/Card/8fdd4555-6e96-4526-99d45c9cf0fe4d6e (accessed 25 August 2019).

7. Reshenie Arbitrazhnogo suda Novosibirskoy oblasti po delu ot 29.03.2019№ A45-17427/2018 [The
Decision of the Arbitration Court of the Novosibirsk Region in Case No A45-17427/2018 Dated March 29, 2019]. URL: https://kad.arbitr.ru/Card/433a97a1-6fof4049-b758-9f591b6b4480 (accessed 22 August 2019).

8. Savelyev A.I. Elektronnaya kommertsiya $v$ Rossii $i$ za rubezhom: pravovoe regulirovanie [E-Commerce in Russia and Abroad: Legal Regulation]. Moscow, Statut Publ., 2016. 640 p.

9. Bakos Ya., Marotta-Wurgler F., Trossen D.R. Does Anyone Read the Fine Print? Consumer Attention to Standard Form Contracts. Journal of Legal Studies, 2014, January, vol. 43, no. 1, pp. 1-35. DOI: http:// dx.doi.org/10.2139/ssrn.1443256.

10. Council Directive 93/13/EEC of 5 April 1993 on unfair terms in consumer contracts. URL: https://eur-lex.europa.eu/LexUriServ/LexUriServ.do? uri=CELEX:31993L0013:en:HTML (accessed 28 August 2019).

\section{Information about the Author}

Marina Yu. Kozlova, Candidate of Sciences (Jurisprudence), Associate Professor, Leading Researcher, Volgograd State University, Prosp. Universitetsky, 100, 400062 Volgograd, Russian Federation, kozlova@volsu.ru, https://orcid.org/0000-0002-6651-4392

\section{Информация об авторе}

Марина Юрьевна Козлова, кандидат юридических наук, доцент, ведущий научный сотрудник, Волгоградский государственный университет, просп. Университетский, 100, 400062 г. Волгоград, kozlova@volsu.ru, https://orcid.org/0000-0002-6651-4392 